\title{
Assistência financeira do FNDE/MEC a programas e projetos educacionais: formato e implicações
}

Cláudia da Mota Darós

Parente

Palavras-chave: financiamento da educação; descentralização; política educacional; salárioeducação.

\section{Resumo}

Descreve o formato da Assistência Financeira do Fundo Nacional de Desenvolvimento da Educação (FNDE) para programas e projetos educacionais, via Plano de Trabalho Anual (PTA), relacionando seus aspectos institucionais, técnicos, financeiros e políticos. A partir da análise documental e legal sobre a Assistência Financeira do FNDE e de entrevistas com técnicos e gestores do FNDE, verifica as implicações do formato da Assistência Financeira nas políticas de financiamento da educação.

\section{Introdução}

As discussões relativas ao financiamento educacional brasileiro ganharam maior visibilidade nas últimas décadas. No final dos anos 90, o Fundo de Manutenção e Desenvolvimento do Ensino Fundamental e de Valorização do Magistério (Fundef) concentrou a maior parte das atenções. Em que pese a sua importância no financiamento educacional, bem como a sua abrangência, o presente artigo destaca a necessidade de não distanciar da agenda social e política a análise e o estudo de outras formas de financiamento da educação, como é o caso da Assistência Financeira do FNDE, enfatizada por este artigo.

O financiamento da educação, mais do que importante instrumento para a implementação das políticas sociais, constitui-se um determinante do padrão de intervenção do Estado nas políticas educacionais. O formato assumido por esse padrão de financiamento tem moldado os direcionamentos e os rumos das políticas.

O histórico do financiamento da educação aponta o peso do Estado centralizador na definição do gasto em educação, reflexo da Reforma Tributária de 1966, que promoveu grande centralização financeira e fiscal. No entanto, os anos 1980 marcaram a abertura democrática, formando terreno fértil para a defesa da descentralização.

A política de descentralização está associada à divisão de responsabilidades entre as três esferas governamentais, de modo que suas ações sejam complementares e dêem conta das necessidades sociais. No entanto, uma das principais problemáticas do financiamento público refere-se, justamente, à ausência de delimitação clara das competências nas diversas instâncias governamentais. Isso significa que a efetivação de uma política de descentralização que não considere tal problemática pode até mesmo agravar as disparidades regionais.

A discussão sobre o processo de divisão de responsabilidades entre as esferas governamentais, principalmente quando se trata de responsabilidades relativas ao gasto de recursos públicos, traz a necessidade da definição de dois conceitos básicos: descentralização e desconcentração. Apesar da diversidade e abrangência desses 
conceitos, não é intenção deste artigo apresentar todas as suas variações, mas, sim, traçar algumas aproximações com os objetivos do estudo.

De acordo com Médici e Maciel (1996), na desconcentração, as esferas centrais são responsáveis pelo gasto, embora ele seja realizado no âmbito local, por intermédio de um órgão do governo central. Exemplos disso são as extintas Delegacias do Ministério da Educação (Demec).

Na descentralização, a responsabilidade pelo gasto é repassada às esferas governamentais locais (estaduais ou municipais). Os autores definem dois tipos de descentralização: dependente e autônoma.

A descentralização dependente é aquela em que o gasto é financiado por uma esfera de ordem superior, ou seja, em que a esfera local depende dos recursos da esfera hierarquicamente superior. A descentralização autônoma é aquela em que a própria esfera local financia os gastos realizados.

Médici e Maciel (1996) subdividem a descentralização dependente em duas vertentes: tutelada e vinculada. A descentralização dependente tutelada seria aquela proveniente das transferências negociadas, mantendo uma relação frágil de dependência entre a esfera local e a central, vulnerável aos aspectos políticos e institucionais. A descentralização dependente vinculada seria aquela proveniente de transferências automáticas, embasadas em aspectos legais.

Este artigo pretende justamente mostrar o formato e as implicações da descentralização dependente tutelada, mediante a análise da Assistência Financeira do Fundo Nacional de Desenvolvimento da Educação (FNDE) a programas e projetos educacionais, via Plano de Trabalho Anual (PTA).

Parte das análises apresentadas foi retirada da Dissertação de Mestrado em Educação defendida pela autora (Parente, 2001). O referido estudo baseou-se em dados provenientes da pesquisa de campo, a partir da análise documental e de entrevistas com técnicos e gestores do FNDE/MEC. A divulgação dessa pesquisa, além de contribuir para a área educacional, pretende suprir, em parte, a ausência de estudos relativos a essa forma de financiamento.

\section{O FNDE}

O FNDE é uma autarquia do Ministério da Educação (MEC) cuja finalidade principal é a captação de recursos financeiros e sua canalização para o financiamento de programas e projetos educacionais, nas áreas de ensino, pesquisa, alimentação, material escolar, entre outros.

A criação do FNDE, ocorrida em meio ao regime militar, é parte de uma tendência descentralizadora diante de um contexto centralizador. Médici e Maciel (1996) descrevem o surgimento dos fundos públicos sociais no período pós-64 e os principais mecanismos de acesso a eles, demonstrando a presença dos critérios de dependência dos Estados e municípios em relação ao governo federal. No entanto, enfatizam a importância dos fundos sociais, no Brasil, para o financiamento das políticas sociais, por garantirem fontes adicionais de investimento em programas sociais.

Até 1997, o MEC contava com o apoio da Fundação de Assistência ao Estudante (FAE), que executava programas educacionais com recursos do Tesouro Nacional e do FNDE. Nesse mesmo ano, a FAE foi extinta com o objetivo de dar continuidade à política de descentralização do governo federal, oferecendo maior racionalidade ao processo de financiamento da educação básica e propiciando um melhor atendimento às escolas e alunos beneficiados. Todas as atribuições que, antes, eram de responsabilidade da FAE ficaram a cargo do FNDE. Dessa forma, a autarquia incorporou os objetivos da FAE em desenvolver programas de assistência ao estudante, oferecendo apoio aos Estados e municípios na concretização de programas suplementares de distribuição de material escolar, didático-pedagógico, merenda escolar e assistência à saúde (Castro, 2000).

O FNDE financia e gerencia um grupo extenso de ações e programas assistenciais e de apoio ao desenvolvimento educacional. Entre estes últimos estão o Programa Dinheiro Direto na Escola (PDDE), o Programa Nacional do Livro Didático (PNLD), o Programa Nacional Biblioteca da Escola (PNBE), a TV Escola, o Programa Nacional de Informática na Educação (Proinfo), o Fundo de Fortalecimento da Escola (Fundescola), o Fundo de Manutenção e Desenvolvimento do Ensino Fundamental e de Valorização do Magistério (Fundef) e o Programa de Aceleração da Aprendizagem (Brasil/MEC/FNDE, 2000).

Em consonância com alguns desses programas e ações, o FNDE oferece assistência financeira a programas e projetos educacionais mediante a aprovação de Planos de Trabalho Anuais (PTAs) de órgãos 
governamentais e não-governamentais, em sua maior parte, proveniente dos recursos da quota federal do Salário-Educação.

\section{O salário-educação}

A análise da Assistência Financeira do FNDE está diretamente articulada à análise dos recursos do Salário-Educação, dada a relevância destes na composição do Fundo.

O Salário-Educação é uma contribuição social, citada no $\S 5^{\circ}$ do art. 212 da Constituição Federal, de 1988, no art. $4^{\circ}$ da Emenda Constitucional n ${ }^{\circ} 14$, de 1996, no art. 68 da Lei de Diretrizes e Bases da Educação Nacional (Lei no 9.394, de 1996) e no art. 15 da Lei $n^{\circ}$ 9.424, de 1996, constituindo-se uma fonte adicional de financiamento ao ensino fundamental público.

A contribuição do Salário-Educação é feita pelas empresas, tomando-se como referência a alíquota de 2,5\% (dois e meio por cento) sobre o total de remunerações pagas ou creditadas, a qualquer título, aos segurados empregados.

O Salário-Educação foi criado a partir da Lei $\mathrm{n}^{0} 4.440$, de 27/10/64, cuja finalidade específica era combater o analfabetismo. Ao longo de sua história, suas finalidades, formato e modos de arrecadação sofreram alterações. Entretanto, até hoje é uma das principais fontes do financiamento educacional, delineando um importante papel na consolidação das políticas sociais na área educacional.

Quando surgiu, o Salário-Educação era distribuído em duas quotas: quota federal e quota estadual, repassada aos Estados arrecadadores. Atualmente, além dessas duas, existe a quota municipal (Lei $\mathrm{n}^{\circ}$ 9.766, de 1998, e Lei $n^{\circ} 10.832$, de 2003).

Para este estudo, interessa ressaltar a importância do Salário-Educação para o financiamento da educação brasileira, de um modo geral, e, mais especificamente, dos recursos da quota federal, administrados pelo FNDE e aplicados no financiamento de programas e projetos voltados para a universalização do ensino fundamental.

Na história do Salário-Educação, o Decreto $\mathrm{n}^{\mathrm{O}}$ 88.374, de 1983, vinculou $25 \%$ dos recursos da quota federal ao antigo ensino de primeiro grau municipal. Com isso, os municípios passaram a ter acesso aos recursos do FNDE mediante a apresentação de projetos específicos sob a forma de Plano de Trabalho.
De acordo com Melchior (1987), antes do referido decreto, várias oportunidades foram perdidas no que diz respeito à descentralização dos recursos do SalárioEducação para os municípios.

Nos anos 80, a municipalização dos recursos da quota federal do Salário-Educação, além de reduzir as receitas dos governos estaduais, foi parte da estratégia do Ministério da Educação de municipalizar o ensino, embora a forma adotada - sem o fornecimento das devidas condições - tenha inibido a construção de uma real municipalização.

Nesse mesmo período, com a instituição das eleições para governadores estaduais, a discussão sobre os montantes arrecadados e os efetivamente distribuídos entre os Estados passava também pela questão política. Sendo assim, municipalizar os recursos do Salário-Educação significou acabar com intermediários - principalmente os governos de oposição - e estabelecer uma relação direta com as prefeituras municipais (Velloso, 1987).

Ressalta-se, assim, a relevância do Salário-Educação na composição da receita do FNDE, embora seja necessário ressaltar também a existência de outras receitas que compõem o Fundo. ${ }^{1}$

\section{A assistência financeira do FNDE via Plano de Trabalho Anual (PTA)}

Anualmente, o FNDE define normas, parâmetros e orientações aos órgãos governamentais e não-governamentais que pretendam elaborar projetos para assistência financeira mediante Planos de Trabalho.

De acordo com o FNDE, a partir dos anos 1990 e mais efetivamente a partir de 1995, a formulação dos manuais de orientações passou a ser realizada, de forma conjunta, por técnicos e gestores do FNDE e do MEC.

Conforme os técnicos do FNDE e do MEC, os manuais são elaborados e reformulados a partir da experiência e da prática que realizam, da constatação de mudanças necessárias ao aprimoramento do processo, bem como das metas estabelecidas para a política educacional como um todo. Por isso, as reformulações das normas geralmente contam com a participação de representantes de todos os setores envolvidos no processo de assistência financeira, pertencentes ao FNDE e às secretariasfim do MEC. 
O histórico das normas e procedimentos para assistência financeira comprova a evolução que sofreram ao longo das décadas de 80 e 90. Exemplos disso são os próprios manuais que delimitam as ações passíveis de assistência financeira. Devido à crescente transparência dos critérios técnicos - mesmo ainda não suficientes - e à crescente informatização do processo de assistência financeira, as transformações temporais foram bastante aparentes, embora muito ainda deva ser feito para evitar as interferências políticas, a inconstância e a inexatidão dos critérios técnicos.

$\mathrm{O}$ estudo que culminou no presente artigo analisou a Assistência Financeira do FNDE de 1997 a 1999, período em que a autarquia publicou dois manuais de assistência financeira. No ano de 1997, publicou a "Sistemática de Financiamento do Ensino Fundamental". Em 1998, o financiamento foi realizado a partir dos mesmos parâmetros de 1997. Em 1999, publicou as "Normas para Assistência Financeira a Programas e Projetos Educacionais".

Embora o processo de assistência financeira esteja informatizado, o longo percurso realizado pelos PTAs e a dificuldade em se respeitar os prazos estabelecidos - tanto por parte dos órgãos solicitantes como do FNDE - têm provocado atrasos constantes nos cronogramas de concessão de recursos.

A Assistência Financeira de 1997 contemplou as seguintes modalidades de ensino: Educação Pré-Escolar, Ensino Fundamental Regular, Educação de Jovens e Adultos, Educação Indígena e Educação Especial. Entre as ações financiáveis: ampliação, construção e reforma de escola; aquisição de equipamentos e de material didático-pedagógico; capacitação de recursos humanos; transporte do escolar; saúde do escolar.

No entanto, de acordo com a Resolução $n^{\circ}$ 05/1997, algumas ações constituíram-se prioridades de financiamento. Foram aquelas ações relacionadas: a programas de aceleração de aprendizagem; ao programa de alfabetização solidária; ao programa de apoio tecnológico; à realização do Censo Escolar e de avaliações educacionais; aos assentamentos rurais implantados pelo Incra; aos municípios que apoiassem e mantivessem programas federais de erradicação do trabalho infantil.

De acordo com os gestores do FNDE, a Sistemática de Financiamento de 1997 modificou muito em relação à Sistemática de 1995. O seu formato, muito mais técnico e rigoroso, foi uma das causas do retardamento de todo o processo e, conseqüentemente, da aprovação dos projetos.

Assim, o grande volume de processos e o formato mais criterioso da Sistemática de 1997 fizeram com que ela fosse utilizada em 1998. Isso ficou estabelecido a partir da Resolução $\mathrm{n}^{0}$ 01, de 20/01/98, na qual o FNDE, dispondo sobre o financiamento de projetos educacionais, definiu que os órgãos interessados em realizar solicitações de recursos através do Plano de Trabalho Anual deveriam cumprir os mesmos parâmetros e critérios estabelecidos na Sistemática de Financiamento de 1997.

O Conselho Deliberativo do FNDE, em 21/01/1999, publicou a Resolução n ${ }^{\circ}$ 04, definindo as Normas para Assistência Financeira a Programas e Projetos Educacionais (NAFPPE). As Normas de 1999 contemplaram os seguintes níveis e modalidades de ensino: Educação Pré-Escolar, Ensino Fundamental, Educação de Jovens e Adultos, Educação Escolar Indígena e Educação Especial. As ações e programas financiáveis foram: formação continuada/capacitação de professores e técnicos; material didático-pedagógico, equipamentos para escolas, manutenção física de escolas, adaptação de escolas, Programa Aceleração de Aprendizagem, Programa de Apoio Tecnológico, Programa Nacional de Transporte do Escolar.

Em 1999, as NAFPPE priorizaram a formação continuada dos professores e a produção, aquisição e impressão de material didático-pedagógico para todos os níveis e modalidades de ensino. As construções, reformas e ampliações não mais se constituíram objeto de assistência financeira do FNDE. Rosar e Sousa (1999) ressaltam essa tendência, pois já no início dos anos 90 o MEC passou a desestimular ações de construções escolares.

O Programa Aceleração de Aprendizagem, o Programa de Apoio Tecnológico e a capacitação de professores foram priorizados com o objetivo de diminuir o problema da distorção idade-série.

\section{Plano de Trabalho Anual (PTA): formato e implicações}

As principais questões que incidem diretamente na Assistência Financeira do FNDE aos municípios brasileiros referem-se: ao seu formato, à descontinuidade, à instabilidade 
orçamentária, à permeabilidade política e à imprecisão dos critérios de aprovação.

No histórico do FNDE, pode-se verificar que a Assistência Financeira aos órgãos governamentais sempre ocorreu mediante a apresentação de projetos, mais especificamente de Plano de Trabalho. E justamente por serem os recursos solicitados na forma de Plano de Trabalho Anual (PTA) é que a Assistência Financeira do FNDE ficou conhecida por este nome, mesmo não se constituindo um programa propriamente dito.

Os Planos de Trabalho são, na verdade, constituídos de formulários nos quais os órgãos apresentam as suas propostas de trabalho para um determinado período, seus objetivos, suas necessidades e a forma de aplicação dos recursos solicitados.

No entanto, embora o formato de Plano de Trabalho remonte à década de 60 (para os municípios, década de 80), os procedimentos e as regras da Assistência Financeira e, conseqüentemente, para o preenchimento dos formulários sofreram algumas alterações, embora o formato PTA permaneça atualmente.

De acordo com Rosar e Sousa (1999), essa sistemática de assistência financeira, no final dos anos 1980, foi sendo simplificada em termos de forma e conteúdo.

Essas alterações são perceptíveis quando se analisam vários dos manuais editados pelo FNDE/MEC para apresentação das ações financiáveis anualmente. Essas alterações refletem justamente o arcabouço técnico necessário aos diversos órgãos solicitantes para elaboração e execução dos Planos de Trabalho.

A descontinuidade é também item de discussão no que se refere ao PTA. Não se constituindo uma política ou um programa propriamente dito, e sim um instrumento de solicitação de recursos e um meio pelo qual determinados programas são implementados, o PTA submete-se às políticas e diretrizes do Ministério da Educação e, por isso mesmo, está condicionado às instabilidades políticoadministrativas do processo decisório.

Por não possuir instrumentos que assegurem a continuidade das suas solicitações, o PTA acaba sofrendo diversas críticas no que diz respeito à aplicação dos recursos federais. A Sistemática de Convênios adotada pelo FNDE para repassar os recursos aos órgãos que tenham seus PTAs aprovados não garante a continuidade dos projetos elaborados. Há um caráter de adequação dos projetos às prioridades estabelecidas pela esfera federal a cada ano, sem que se considere mais atentamente a política educacional de um modo geral e as ações prioritárias que dela devem resultar. Esse aspecto já era ressaltado no início dos anos 1990 por Mello e Silva (1992).

Além disso, sugere a inviabilidade de uma política conjunta entre as esferas governamentais. Embora a Assistência Financeira se paute nas políticas educacionais nacionais definidas pelo MEC, as solicitações são realizadas individualmente pelas instâncias governamentais (estadual, municipal ou do Distrito Federal), sem um planejamento entre elas, correndo-se o risco de concorrência entre as redes de ensino.

$\mathrm{O}$ aspecto da descontinuidade remete a uma outra questão: a instabilidade da arrecadação do Salário-Educação. Em primeiro lugar, há que se resgatar os próprios objetivos do FNDE como instituição responsável por corrigir disparidades regionais; ou seja, ele não tem a finalidade de atender a totalidade dos órgãos governamentais e não-governamentais solicitantes. Por isso diz-se que ele não financia projetos e sim oferece assistência financeira. Assim, o FNDE presta assistência financeira a órgãos solicitantes nos quais se evidenciem necessidades, e mais, que estas necessidades estejam inscritas nas prioridades para assistência financeira.

Em segundo lugar, a arrecadação do Salário-Educação está vinculada à folha de salários das empresas, o que significa a sua adesão às instabilidades do mercado de trabalho.

Não há como dissociar a instabilidade de arrecadação do Salário-Educação da descontinuidade e formato do PTA. Um item relaciona-se ao outro, uma vez que a continuidade ou não dos projetos aprovados se dá, em grande medida, pela existência ou não de recursos. E o seu formato acaba tendo continuidade, talvez, pela própria instabilidade dos recursos. $\mathrm{O}$ fato é que a descontinuidade faz emergir o problema da eficiência e eficácia da aplicação dos recursos federais. Ainda que os recursos sejam escassos, ainda que o FNDE não tenha como objetivo atender a todos os solicitantes, ainda que as ações financiáveis sofram alterações, algumas ações poderiam ser direcionadas para a garantia de que os poucos recursos que são aplicados sejam realmente bem aplicados.

Ao fragmentar as ações educacionais e distribuir recursos financeiros sem um adequado conjunto de propostas a serem viabilizadas para a correção das desigualdades na educação pública, a sistemática de 
convênios confirma a inexistência de um sistema de fiscalização da aplicação dos recursos educacionais, ao mesmo tempo em que as esferas governamentais, de um modo geral, não desenvolvem políticas de educação em conjunto, uma vez que suas ações, muitas vezes, ao invés de se complementarem, divergem e concorrem entre si.

Um outro aspecto relevante, responsável por muitas das críticas ao formato da Assistência Financeira do FNDE, refere-se à permeabilidade política.

As transferências dos recursos da quota federal do Salário-Educação, via Plano de Trabalho Anual, são chamadas de transferências negociadas, devido ao "alto grau de imprevisibilidade e sensibilidade a fatores político-partidários, tornando difícil alcançar racionalidade na programação financeira" (Gomes, 1992, p. 50).

A análise da Assistência Financeira do FNDE no contexto atual mostra justamente a continuidade de um padrão de financiamento alertado por alguns autores como inadequado.

A sistemática de convênios adotada pelo FNDE constituiu-se, ao longo dos anos de sua existência, um aparato político das esferas envolvidas, uma vez que o espaço para negociação entre elas é muito mais visível. Nesse sentido, as formas e os critérios estabelecidos na sistemática de financiamento mesclam-se com as mais diversas instâncias políticas, em forma de negociações e reclames dos atores envolvidos, determinando o caráter aberto e flexível do processo de transferência dos recursos em questão.

E se as negociações acabam por ter um peso significativo no repasse das transferências, as instâncias cuja representatividade política é mais visível acabam sendo privilegiadas. Conseqüentemente, os municípios e Estados com maior capacidade política têm maiores chances de se beneficiarem dos recursos federais (Xavier et al., 1992).

Embora essa questão tenha sido muito mais enfática na década de 80 e esforços tenham sido empreendidos na minimização das negociações políticas, algumas práticas políticas ainda são utilizadas na determinação da aprovação dos PTAs. Se nos anos 80 as negociações determinavam a aprovação deste ou daquele projeto, referente a este ou àquele município, com um determinado valor específico, atualmente, os níveis de negociação política, ainda que diminutos, inscrevem-se na aceleração dos repasses, na atenção especial a determinadas regiões ou municípios, entre outros.

Assim, embora as negociações tenham sido reduzidas - principalmente a partir das gestões recentes -, o fato é que o formato do PTA ainda é suficientemente flexível para abrir espaços a infiltrações políticas. E se essas infiltrações políticas podem não mais servir para ajustar-se aos mais diversos interesses, podem ao menos significar, no âmbito federal, a aprovação de projetos específicos a órgãos determinados - que podem ou não estar contemplados nos manuais de assistência financeira - e, no âmbito local, a continuidade do peso da representatividade política.

Os apontamentos acerca da flexibilidade da sistemática de convênios e do quanto é permeável às negociações políticas possibilitam maior entendimento dos processos decisórios a respeito dos gastos públicos em educação, no que se refere mais propriamente aos condicionantes políticos e institucionais. Daí a relevância de estudos que busquem compreender como as variáveis políticas e institucionais interferem na trajetória dos gastos públicos.

O aspecto político acaba tendo um papel importante, dada a imprecisão dos critérios para aprovação dos projetos. Por outro lado, o histórico da Assistência Financeira mostra os progressos ocorridos em termos de procedimentos técnicos adotados para aprovação dos PTAs. E por isso ressaltam-se os avanços na delimitação, ao longo do tempo, dos critérios de repasse de recursos.

Essa preocupação com a definição de critérios ocorreu, em primeiro lugar, devido ao aumento da demanda de projetos e redução progressiva dos recursos do SalárioEducação, e, em segundo lugar, para fazer prevalecer o aspecto técnico sobre o político, diminuindo o peso das negociações e da barganha política.

No entanto, embora os critérios técnicos tenham evoluído, a sua falta de clareza acaba impedindo a total credibilidade na sua utilização.

Além disso, há que ressaltar a tendência descentralizadora dos atuais programas e ações do Ministério da Educação (Draibe, 1999). E nesse aspecto deve-se chamar a atenção para o Programa Dinheiro Direto na Escola (PDDE), criado em 1995, caracterizado como uma descentralização dependente vinculada. Diferentemente da Assistência Financeira do FNDE via PTA (descentralização dependente tutelada), o PDDE utiliza critérios pré-definidos e 
universalizantes, baseando-se no número de alunos matriculados nas escolas.

É claro que, ao contrário do PDDE, que possui um caráter universalizante, a Assistência Financeira do FNDE tem como principal objetivo a correção de disparidades regionais. Ressalta-se, entretanto, que, independentemente dos seus objetivos e mesmo da instabilidade da arrecadação dos recursos do Salário-Educação, seria necessário o estabelecimento de uma política de distribuição transparente com critérios prédefinidos.

Assim, em que pesem todos os inconvenientes advindos do formato da Assistência Financeira, deve-se ressaltar que o repasse da quota federal do Salário-Educação via PTA aos municípios, mesmo em face do peso dos recursos do Fundef (bem mais significativo), tem sido uma boa alternativa para a complementação dos recursos municipais, uma vez que se caracteriza como um canal de acesso direto dos municípios aos recursos federais. Daí a importância de repensar seu formato, sua permeabilidade política e de melhor definir as ações a serem financiáveis e os critérios para aprovação dos PTAs.

\section{Considerações finais}

O presente artigo buscou apreender a Assistência Financeira do FNDE a programas e projetos educacionais, seu formato, implicações e possibilidades, evidenciando um modelo de gestão dos recursos federais.

A Assistência Financeira do FNDE possui limitações quanto à aplicação dos recursos da quota federal do Salário-Educação, principalmente devido ao seu formato: solicitação de recursos via Plano de Trabalho e recebimento de recursos via Convênios.

Embora haja a defesa da ampliação dos recursos da Assistência Financeira, compreende-se que, com esse formato, é inviável qualquer forma de universalização. Isto porque muito na frente de qualquer intenção de ampliação da participação estão os objetivos da própria Assistência Financeira do FNDE: a correção das disparidades regionais. Tais objetivos, portanto, não contemplam formas de universalização e são partes de uma política suplementar.

Além disso, o aspecto financeiro também acaba por ser significativo, pois ele irá delimitar os montantes disponíveis, as ações a serem contempladas ou não e os órgãos a serem beneficiados. A incerteza decorrente da arrecadação do Salário-Educação impossibilita a adesão a uma descentralização dependente vinculada, como é o caso do PDDE, na medida em que a instabilidade dos montantes arrecadados traria indefinições aos montantes a serem aplicados.

Mas, ainda que a Assistência Financeira do FNDE tenha objetivos suplementares, a delimitação de critérios melhor definidos, tanto para a participação dos órgãos solicitantes como para a aprovação dos projetos, auxiliaria numa execução mais eficiente dos objetivos da autarquia. Isto porque ainda é visível o grande número de projetos elaborados. Na medida em que o FNDE abre espaço para que todos façam suas solicitações, ao mesmo tempo cria margem para frustrações e, acima de tudo, despende esforços e recursos dos órgãos solicitantes enquanto elaboram seus projetos e da autarquia enquanto os analisa.

Para ilustrar essa questão, cabe destacar as ações e programas privilegiados no Manual de Assistência Financeira de 2004: Educação Infantil, Ensino Fundamental, Educação de Jovens e Adultos, Educação Escolar Indígena, Educação Especial, Cultura Afro-Brasileira - Áreas Remanescentes de Quilombos, Correção do Fluxo Escolar Aceleração da Aprendizagem, Programa Paz nas Escolas, Programa Nacional de Transporte Escolar, Programa Nacional de Saúde do Escolar, Programa Brasil Alfabetizado, Ações Educativas Complementares, Ações de Apoio Educacional.

Tais considerações acerca de possíveis mudanças na Assistência Financeira não devem ser entendidas nem como defesa da perda de uma alternativa de Assistência Financeira aos diversos órgãos solicitantes, entre eles o município, nem do formato da Assistência vigente. Ao contrário, devem ser entendidas como: sugestões à melhoria do processo que se encontra em andamento; visualização de um modelo repleto de problemas; justificativas à necessidade de alterações desse modelo.

Durante a pesquisa de campo, as entrevistas realizadas no âmbito federal indicaram perspectivas e expectativas quanto a um processo de mudança, em grande medida pelo contexto descentralizador vivenciado pela área educacional e pela difusão de novas formas de gestão financeira.

Assim, empreendidos esforços para que a própria autarquia reveja seus objetivos e reformule o formato de sua Assistência Financeira, há que, conjuntamente, articular 
ações no sentido de garantir que seus objetivos, quando da implementação dos projetos educacionais, sejam de fato alcançados. Isto significa lançar mão de instrumentos que garantam que os recursos repassados aos órgãos beneficiários sejam não somente aplicados nos devidos objetos conveniados e com eficiência, mas, acima de tudo, sejam aplicados em locais onde sejam visíveis as necessidades.
Ainda são parcos os instrumentos da autarquia para a consecução desse acompanhamento e fiscalização. Apesar de algumas ações em termos de auditoria e de acompanhamento de convênios, a verificação da aplicabilidade dos recursos federais é realizada, basicamente, através das informações contidas nas prestações de contas, limitando-se, portanto, ao aspecto técnicofinanceiro.

\section{Referências bibliográficas}

BRASIL. Lei $n^{\circ}$ 4440, de 27 de outubro de 1964. Disponível em: <www.senado.gov.br>.

. Decreto $n^{\circ}$ 88374, de 7 de junho de 1983. Disponível em: <www.senado.gov.br $>$.

. Constituição (1988). Constituição da República Federativa do Brasil: promulgada em 5 de outubro de 1988. Disponível em: <www.senado.gov.br>.

Emenda Constitucional $n^{o}$ 14, de 12 de setembro de 1996. Disponível em: $<$ www.senado.gov.br>.

. Lei $\mathrm{n}^{\circ}$ 9394, de 20 de dezembro de 1996. Estabelece as diretrizes e bases da educação nacional. Disponível em: <www.senado.gov.br>.

. Lei $n^{\circ}$ 9494, de 24 de dezembro de 1996. Dispõe sobre o Fundo de Manutenção e Desenvolvimento do Ensino Fundamental e de Valorização do Magistério. Disponível em: $<$ www.senado.gov.br $>$.

. Lei $n^{\circ}$ 9766, de 18 de dezembro de 1998. Altera a legislação que rege o SalárioEducação. Disponível em: <www.senado.gov.br>.

. Lei $n^{o}$ 10832, de 29 de dezembro de 2003. Altera a legislação que rege o SalárioEducação. Disponível em: <www.senado.gov.br>.

. Ministério da Educação. Fundo Nacional de Desenvolvimento da Educação (FNDE). Relatório de Atividades 1999. Brasília: MEC/FNDE, 2000.

. Normas para Assistência Financeira a Programas e Projetos Educacionais. Brasília: MEC/FNDE, 1999.

. Sistemática de Financiamento do Ensino Fundamental. Brasília: MEC/FNDE, 1997.

. Conselho Deliberativo do Fundo Nacional de Desenvolvimento da Educação. Resolução $n^{\circ}$ 5, de 26 de maio de 1997.

. Resolução $n^{o}$ 1, de 20 de janeiro de 1998.

. Resolução $n^{o}$ 4, de 21 de janeiro de 1999. 
CASTRO, Jorge Abrahão de. Avaliação do processo de gasto público do Fundo Nacional de Desenvolvimento da Educação (FNDE). Brasília: Ipea, 2000. (Textos para Discussão, n. 760). Disponível em: <http://www.ipea.gov.br/pub/td/td_2000/td0760.pdf>.

DRAIBE, S. M. A experiência brasileira recente de descentralização de programas federais de apoio ao ensino fundamental. In: COSTA, V. L. C. Descentralização da educação: novas formas de coordenação e financiamento. São Paulo: Fundap; Cortez, 1999. p. 68-98.

GOMES, C. A. Financiamento e eqüidade. In: GOMES, C. A.; SOBRINHO, J. A. (Org.). Qualidade, eficiência e eqüidade na educação básica. Brasília: Ipea, 1992. p. 47-69. (Série Ipea, n. 136).

MEDICI, A. C.; MACIEL, M. C. M. P. A dinâmica do gasto social nas três esferas de governo: 1980-1992. In: ALMEIDA, M. H. T. de et al. Descentralização e políticas sociais. São Paulo: Fundap, 1996. p. 41-105.

MELCHIOR, J. C. de A. O financiamento da educação no Brasil. São Paulo: EPU, 1987.

MELLO, G. N. de; SILVA, R. N. Política educacional no Governo Collor: antecedentes e contradições. São Paulo: Fundap, Iesp, 1992. (Textos para Discussão, n. 3).

PARENTE, C. da M. D. O processo decisório de implementação da assistência financeira do Fundo Nacional de Desenvolvimento da Educação (FNDE), via Plano de Trabalho Anual (PTA), no município de Vinhedo-SP (1997-1999). Campinas, 2001. Dissertação (Mestrado em Educação) - Faculdade de Educação, Universidade Estadual de Campinas.

ROSAR, M. de F. F.; SOUSA, M. S. de. A política de municipalização no Estado do Maranhão: alguns aspectos contraditórios. In: OLIVEIRA, C. de et al. Municipalização do ensino no Brasil. Belo Horizonte: Autêntica, 1999. p. 91-121.

VELLOSO, Jacques. Financiamento das políticas públicas: a educação. In: POLÍTICAS públicas e educação. Brasília: Inep, 1987. p. 103-122. (Série Encontros e Debates; 1)

XAVIER, A. C. da R. et al. Os padrões mínimos de qualidade dos serviços educacionais: uma estratégia de alocação de recursos para o ensino fundamental. In: GOMES, C. A.; SOBRINHO, J. A. (Org.). Qualidade, eficiência e eqüidade na educação básica. Brasília: Ipea, 1992. p. 71-97. (Série Ipea, n. 136).

Cláudia da Mota Darós Parente, doutoranda em educação na Universidade Estadual de Campinas (Unicamp), na área de Políticas de Educação e Sistemas Educativos, é professora do Curso de Pedagogia da Pontifícia Universidade Católica de Minas Gerais (PUCMinas - Campus Poços de Caldas), do Curso Normal Superior das Faculdades de Valinhos e do Curso de Pedagogia da Faculdade Comunitária de Campinas. É membro do Instituto de Pesquisa do Terceiro Setor (Ipets).

claudiadaros@hotmail.com

\section{Abstract}

Financial assistance of FNDE/MEC to educational programs and projects: format and implications

This article describes the structure of the Financial Assistance of the National Fund of Education Development (Fundo Nacional de Desenvolvimento da Educação - FNDE) for 
educational programs and projects, by considering the Annual Working Plan (Plano de Trabalho Anual - PTA) and by relating its institutional, technical, financial and political aspects. After documental and legal analysis on the FNDE Financial Assistance and after making interviews with experts and managers of FNDE, it was possible to verify the results of the Financial Assistance structure on the education financial policies.

Keywords: education financing; decentralization; educational policy; education-salary.

Recebido em 16 de agosto de 2005.

Aprovado em 23 de fevereiro de 2006. 